\title{
DA COLONIALIDADE À DESCOLONIALIDADE: DIÁLOGOS DE CIÊNCIAS A PARTIR DE UMA "EPISTEMOLOGIA DO SUL” - UMA ANÁLISE DE COMUNIDADES QUILOMBOLAS
}

Gissele Leal Bertagnolli*

\begin{abstract}
Resumo
Este artigo aborda o tema "Da colonialidade à descolonialidade: diálogos de ciências a partir de uma epistemologia do sul” e sua relevância se dá pelo processo de descolonização de colônias terem sido marcadas por mudanças nas relações globais, estando essas mudanças relacionadas com o povo quilombola, especialmente comunidades quilombolas da região central do Rio Grande do Sul. O artigo tem como objetivo averiguar alguns aspectos da obra Da colonialidade à descolonialidade: diálogos de ciências a partir de uma "epistemologia do sul", analisando comunidades quilombolas. A metodologia do presente artigo baseia-se em uma pesquisa bibliográfica, tendo como base os textos de Santos e Meneses (2009), podendo ser compreendida como um estudo sistematizado desenvolvido com base em materiais publicados de autores pertinentes para fundamentar a temática abordada e sendo possível reportar e avaliar o conhecimento produzido em pesquisas prévias, destacando conceitos, procedimentos, resultados, discussões e conclusões relevantes.
\end{abstract}

Palavras-chave: Colonialidade. Descolonialidade. Epistemologia.

\footnotetext{
* Mestranda em Desenvolvimento Regional com a linha de pesquisa em Políticas Públicas- UNISC; Mediadora e conciliadora Judicial. Atualmente é Juíza Leiga no Foro da Comarca de São Sepé ,RS . E-mail: adv.gissele@gmail. com
} 


\section{Introdução}

A obra "Epistemologias do Sul" demonstra a vida em grupos, saberes tradicionais e inovadores, processos de qualificação ou desqualificação social, condições de inferioridade, pouca escolarização, algumas características das comunidades quilombolas. Tal obra pretende responder a duas questões: uma que diz respeito às razões que conduziram à eliminação dos contextos culturais da produção do conhecimento e suas consequências; a outra baseia-se na ideia de que o mundo é epistemologicamente diverso e relaciona-se com a possibilidade de afirmação de epistemologias alternativas, tratando sobre a busca de novas referências epistêmicas das ciências humanas.

A obra, dividida em três capítulos e sob o título $D a$ Colonialidade à Descolonialidade, identifica o modo como a diferença epistemológica afirmou-se historicamente, estabelecendo a relação entre a dominação econômica, política e cultural e a dominação epistemológica traduzida na hierarquização dos saberes e na negação da diversidade. Também discute a antiga dicotomia entre tradição e modernidade e a desqualificação dos saberes tradicionais, que foram revelando-se como contraponto à modernidade nas múltiplas resistências à hegemonia dessa mesma modernidade.

Quijano (2005) desenvolve o conceito de colonialidade e, dialogando com a tradição marxista, procura uma interpretação epistemológica da dominação do Norte global sobre o Sul, aqui considerado como América Latina. A colonialidade é constitutiva do poder capitalista, operando, quer nos domínios da vida social, quer nos âmbitos da subjetividade e intersubjetividade, por meio de instrumentos de coerção, tendo em vista a reprodução e perpetuação das relações sociais de dominação.

Um dos conceitos centrais da Epistemologia do Sul, como proposta por Boaventura de Sousa Santos, é a Ecologia de Saberes. $\mathrm{O}$ autor explica que:

[...] como cada saber só existe dentro de uma pluralidade de saberes, nenhum deles pode compreender-se a si próprio sem se referir aos outros saberes [...] os limites e as possibilidades de cada saber residem, assim, em última instância, na existência de outros saberes e, por isso, só podem ser explorados e valorizados na comparação com outros saberes (SANTOS; MENESES, 2009, p. 55). 
A expressão Epistemologias do Sul é uma metáfora da exclusão e do silenciamento de povos e culturas que foram dominados pelo capitalismo e colonialismo. $\mathrm{O}$ conhecimento, os domínios e valores dos povos quilombolas mantêm os vínculos com as raízes ancestrais e permitem ao território, à identidade, à memória uma pratica de resistências que liga o passado ao presente, é o esforço contínuo de existir na situação concreta de vida, é a teoria do conhecimento, o ramo filosófico que se ocupa de pensar os problemas que dizem respeito ao conhecimento.

Santos e Meneses (2009) chamam de Epistemologia do Sul a recuperação dos saberes e práticas dos grupos sociais que, devido ao capitalismo e aos processos coloniais, foram histórica e sociologicamente colocados na posição apenas de objetos ou matéria-prima dos saberes dominantes.

\section{Modernidade/colonialidade: descolonialismo}

"A colonialidade é constitutiva da modernidade, e não derivada" (MIGNOLO, 2005, p. 75). Ou seja, pertencente a um mesmo grupo. Segundo Quijano (2005), colonialismo e colonialidade são dois conceitos relacionados, porém distintos. $\mathrm{O}$ colonialismo refere-se a um padrão de dominação e exploração no qual:

O Colonialismo é, obviamente, mais antigo; no entanto a colonialidade provou ser, nos últimos 500 anos, mais profunda e duradoura que o colonialismo. Porém, sem dúvida, foi forjada dentro deste, e mais ainda, sem ele não teria podido ser imposta à intersubjetividade de modo tão enraizado e prolongado. (QUIJANO, 2005, p. 93).

Santos e Meneses (2009) observam que a modernidade ocidental e o capitalismo são dois processos históricos diferentes. Afinal, o paradigma moderno surgiu antes de o capitalismo industrial tornar-se dominante nos países centrais. "A partir daí, os dois processos convergiram e cruzaram-se, mas, apesar disso, as condições e a dinâmica do desenvolvimento de cada um mantiveram-se separadas e relativamente autônomas" (SANTOS; MENESES, 2009, p. 49).

A diversidade étnico-cultural atribuída à região Sul do Brasil, da qual fazem parte os estados do Rio Grande do Sul, Paraná e Santa Catarina, decorre, em parte, da forma de ocupação do espaço 
geográfico iniciado no período colonial com a imigração europeia. Se comparada estatisticamente ao resto do Brasil, principalmente à Bahia, a região Sul é a área de menos Quilombolas, índios e negros, fazendo-nos pensar que a opressão capitalista exclui socialmente essas comunidades.

Para Santos (2004), a perspectiva pós-colonial parte da ideia de que, a partir das margens ou das periferias, as estruturas de poder e de saber são mais visíveis e a geopolítica do conhecimento ganha um papel fundamental, por problematizar quem produz o conhecimento, em que contexto e para quem. Como define o autor,

Entendo por pós-colonialismo um conjunto de correntes teóricas e analíticas, com forte implantação nos estudos culturais, mas hoje presentes em todas as ciências sociais, que têm em comum darem primazia teórica e política às relações desiguais entre o Norte e o Sul na explicação ou na compreensão do mundo contemporâneo. Tais relações foram constituídas historicamente pelo colonialismo e o fim do colonialismo enquanto relação política não acarretou o fim do colonialismo enquanto relação social, enquanto mentalidade e forma de sociabilidade autoritária e discriminatória (SANTOS, 2004, p. 8).

A colonialidade caracteriza-se por um padrão de poder que deriva da "classificação social da população mundial de acordo com a ideia de raça, uma construção mental que expressa a experiência básica da dominação colonial e que, desde então, permeia as dimensões mais importantes do poder mundial [...]" (QUIJANO, 2005, p. 95).

O pós-colonial refere-se ao período que sucedeu ao processo de descolonização formal das colônias modernas.

Pós-colonialismo é um termo utilizado como categoria conceitual originada nas discussões sobre a descolonização das colônias africanas e asiáticas após a Segunda Guerra Mundial. Nesse contexto, a expressão era utilizada mais frequentemente como um adjetivo, por sociólogos e cientistas políticos, para caracterizar as mudanças nos Estados e nas economias das ex-colônias, que passaram a fazer parte do Terceiro Mundo, uma categoria criada neste mesmo período (CORONIL, 2008, p. 396-398).

Os estudos descoloniais estudam profundamente as raízes da opressão e da vulnerabilidade desses atores de comunidades, 
no marco do processo colonial-moderno, e identificam uma forte razão para esse fenômeno. Segundo Grosfoguel (2008), a perspectiva descolonial não pode basear-se em um universalismo abstrato, mas sim no diálogo entre diversos projetos críticos, políticos, éticos, epistêmicos, apontados para um mundo pluriversal.

O colonialismo em Marx é visto apenas como um estágio historicamente prévio ao capitalismo e ao comunismo e, como a revolução burguesa levando ao capitalismo deveria necessariamente preceder à revolução socialista, a periferia do mundo estaria desde já subtraída da luta revolucionária: "para Marx, el colonialismo no era otra cosa que el pasado de la modernidad y desaparecería por completo con la crisis mundial que daría paso al comunismo" (CASTRO-GÓMEZ, 2005, p. 19). Com o marxismo, a teoria descolonial diverge no sentido de destacar a importância do olhar para as instituições, para a epistemologia e para a cultura como elementos cruciais para a exploração capitalista e para a hierarquização da sociedade.

A colonialidade é um dos elementos constitutivos e específicos do padrão mundial do poder capitalista e funda-se na imposição de uma classificação racial/étnica da população mundial como pedra angular desse padrão de poder (QUIJANO, 2005, p. 93).

Santos (2004) afirma que os furtos do colonialismo não ocorreram apenas extramuros, mas também intramuros. Há, pois, que devolver alguns dos objetos furtados para criar um novo padrão de interculturalidade. Regressar a esses lugares com outro olhar, mais crítico e mais cirúrgico, permitindo a reinvenção do que foi marginalizado, silenciado e esquecido. Santos e Meneses (2009), em Um Ocidente não-ocidentalista: a filosofia à venda, a douta ignorância e a aposta de Pascal, propõe-nos, por meio de uma revisitação, pensar em um novo tipo de relação intercultural e interepistemológica que contribua para a descolonização do saber.

\section{Comunidades quilombolas: da colonialidade à descolonialidade}

A expressão "descolonial" (ou decolonial) não deve ser confundida como mera descolonização.

Em termos históricos e temporais, esta última indica uma superação do colonialismo; por seu turno, a ideia de decolonialidade (ou 

obscura da modernidade, que permanece operando ainda nos dias de hoje em um padrão mundial de poder (BALLESTRIN apud GALLAS; MACHADO, 2013, p. 59).

A problematização das identidades colonizadas e subalternizadas, como a quilombola, a denúncia da permanência das relações de colonialidade e a demonstração das diferentes trajetórias nas sociedades pós-coloniais são válidas contribuições do pós-colonialismo para a elaboração de uma teoria política mais pluriversal e mais atenta às questões das democracias póscoloniais.

A palavra "quilombo", que em sua etimologia bantu quer dizer acampamento guerreiro na floresta, foi popularizada no Brasil pela administração colonial,em suas leis, relatórios, atos e decretos, para referir-se às unidades de apoio mútuo criadas pelos rebeldes ao sistema escravista e às suas reações, organizações e lutas pelo fim da escravidão no país.

As centenas de insurreições de escravos e as formas mais diversas de rejeição ao sistema escravista no período colonial fizeram da palavra "quilombo" um marco da luta contra a dominação colonial e de todas as lutas dos negros que se seguiram após a quebra desses laços institucionais.

Existem quilombos em muitos estados do Brasil, sendo o Rio Grande do Sul um deles, com aproximadamente 130 comunidades quilombolas em território gaúcho, segundo a Federação das Associações das Comunidades Quilombolas do Rio Grande do Sul.

A região contou com a presença de escravos negros desde o início de sua ocupação pelos portugueses, no fim do século XVII. As comunidades remanescentes de quilombos do estado gaúcho são de predominância negra, com atividades socioeconômicas internas que integram a agricultura de subsistência, artesanato e agroindústria.

Existem algumas regiões com grande concentração de quilombos rurais no estado, tais como o litoral, região metropolitana e região central, nesta última destacando-se os municípios de Restinga Seca e Formigueiro.

No final do século XIX, com a quebra dos vínculos coloniais e as mudanças decorrentes dos projetos de industrialização no Brasil, o quilombo ampliou-se para outras parcelas da população, indo da voz dos abolicionistas para os movimentos sociais e 
tornando-se uma parte do projeto político de uma sociedade mais democrática e justa.

O conceito de colonialidade foi construído para contemporizar o colonialismo, lembrando que, mesmo em um mundo supostamente globalizado, as lógicas imperiais e coloniais operam das mais diferentes maneiras, sobretudo nas questões que envolvem as disputas políticas e econômicas entre o Norte e o Sul global.

O quilombo tem uma abrangência ampla de práticas, experiências e significados - sempre dos mais diversos modos de reação às formas de dominação instituídas pelo processo colonial escravista -, ampliando-se para um conjunto incalculável de situações dele decorrentes. Essas reações conferiram ao povo quilombola um significado trans-histórico, o destituindo dos marcos cronológicos e propiciando a relação de continuidade com os direitos pleiteados durante o recente período de redemocratização do país.

Existe uma identidade onde o território quilombola é percebido como um elo entre os sujeitos e destes com seu território, os indivíduos constroem identidades que estão relacionadas em conexão com a terra, havendo o fortalecimento das relações comunitárias pela convergência de interesses comuns propiciadas pela participação de lideranças. A população quilombola habita espaços vistos como segregados, regiões da periferia da cidade ou do campo, pois foram expulsos das regiões centrais da cidade, onde eram vistos como símbolo do não desenvolvimento.

As comunidades de quilombos de qualquer lugar do Brasil são vistas como grupos minoritários que valorizam acentuadamente seus traços culturais diacríticos e suas relações coletivas, a fim de ajustar-se às pressões sofridas.

Com a colonização de diversas regiões do Sul do Brasil, a exclusão social acentuou-se e não se limitou apenas aos contornos da comunidade. Foi estruturado um sistema econômico globalizado de superexploração, com a constituição de novas sociedades de periferia e com populações miscigenadas, a qual construiu um território global demarcado pela ideia de desigualdades e conflitos.

$\mathrm{Na}$ contramão do sistema surgiam as comunidades de resistência, onde diversos indivíduos, sobretudo ex-escravos, tentavam encontrar possibilidades de sobrevivência longe da exploração econômica introduzida pelos capitalistas. 

quilombolas em suas comunidades, apresenta-se em múltiplas dimensões e tende a modificar-se em função do momento histórico, das condições da economia, de fatores culturais e das diversidades regionais.

Porém, esses processos de segregação social não foram estabelecidos basicamente por conta dos fatores internos: tais processos deram-se por meio de diversos fatores que estão inseridos no processo de globalização, cujas transformações em escala mundial atingem espaços que representam o território dos sujeitos excluídos, como é o caso das comunidades de quilombos. Esses fatores de ordem macro são de natureza estrutural, na sua grande maioria, e estão relacionados com o funcionamento global das sociedades: tipo de sistema econômico, regras e imposições do sistema financeiro, modelo de desenvolvimento, estrutura e características das relações econômicas internacionais e estratégias transnacionais.

\section{Considerações finais}

Hoje, as comunidades quilombolas da região central do Rio Grande do Sul estão vivendo um processo de construção identitária. Eles possuem uma identidade étnica, uma ancestralidade comum, que impacta em suas formas de organização política e social. Eles têm consciência que descendem diretamente de ex-escravos africanos e sua característica comum está ligada ao "desenvolvimento de práticas de resistência na manutenção e reprodução de seus modos de vida" (SILVA, 2004, p. 22).

A existência dos quilombos é um tributo à força da resistência africana e afro-brasileira que não se rendeu à servidão colonial, "é até por isso que estes conceitos, quilombo e resistência, fundamentais para a compreensão da história do povo negro no Brasil, parecem fundir-se em um só” (Idem, p. 30).

As comunidades remanescentes de quilombos do RS são de predominância negra, com atividades socioeconômicas internas que integram a agricultura de subsistência, artesanato e agroindústria. Temos muito que aprender com os saberes ancestrais característicos dos povos quilombolas. Para Walsh (2008), o capitalismo imperialista mostra-se ameaçador, tanto por sua dominação, exploração e violência estrutural, como também porque mata a Mãe Terra e leva ao suicídio planetário. 
Quanto à ideia de emancipação social, Boaventura de Sousa Santos ensina que essa ideia não percorre um caminho único: "Não há emancipação em si, mas antes relações emancipatórias" (SANTOS, 2004, p. 250).

Pensamos ser possível encontrar em demais comunidades quilombolas outras epistemologias que fogem aos padrões dominantes, processos em construção, moldados a partir das necessidades. Mesmo que a maioria das comunidades quilombolas não tenham mais uma ligação direta com as práticas e saberes ancestrais, eles intitulam-se como descendentes de escravos que buscam as mesmas coisas que seus antepassados buscavam: dignidade, liberdade, direito a pertencer a um espaço seu.

A exclusão, o colonialismo e o desbaratamento de saberes decorrem da adoção acrítica do modelo dominante de desenvolvimento, definindo um processo de reorientação da construção de sentidos para a realidade por intermédio de ação social.

As tensões geradas pelas graves desigualdades sociais permitiram que fosse reavivada a sabedoria dos povos ancestrais e fez ressurgirem práticas emancipatórias, destinadas ao reconhecimento dos interesses de grupos sociais historicamente excluídos da participação política e social.

Portanto, a colonialidade do ser é pensada como a negação de um estatuto humano para povos quilombolas, por exemplo, na história da modernidade colonial. Essa negação, segundo Walsh (2008), implanta problemas reais em torno da liberdade, do ser e da história do indivíduo subalternizado por uma violência epistêmica.

Walsh (2008) assevera, tendo como referência os movimentos sociais, inclusive os quilombos, que a descolonialidade implica partir da desumanização e considerar as lutas dos povos historicamente subalternizados pela existência, para a construção de outros modos de viver, de poder e de saber.

Sendo assim, pode-se afirmar que a colonialidade do poder construiu a subjetividade do subalternizado, sendo necessário, portanto, segundo Quijano (2005), pensar historicamente a noção de raça. No caráter totalitário da exploração colonial, o colonizador faz do colonizado um povo maléfico, pois a sociedade colonizada não somente define-se como uma sociedade sem valores, como também é o inimigo dos valores. A descolonialidade representa um método que vai além da transformação da descolonização, 
tendo como meta a reconstrução radical do ser, do poder e do saber.

\section{Referências}

CASTRO-GÓMEZ, Santiago. Ciências sociais, violência epistêmica e o problema da "invenção do outro". In: LANDER, Edgardo (Org.). A colonialidade do saber: eurocentrismo e ciências sociais. Perspectivas latino-americanas. Buenos Aires: Clacso, 2005. (Colección Sur Sur).

CORONIL, Fernando. Natureza do pós-colonialismo: do eurocentrismo ao globocentrismo. In: LANDER, Edgardo (Org.). A colonialidade do saber: eurocentrismo e ciências sociais. Perspectivas latino-americanas. Buenos Aires: Clacso, 2008. (Colección Sur Sur).

GALLAS, Luciano; MACHADO, Ricardo. Para transcender a colonialidade. Entrevista com Luciana Maria de Aragão Ballestrin. Online, Revista Instituto Humanitas Unisinos, v. 13, n. 431, nov. 2013. Disponível em: <http://emaberto.inep.gov.br/index.php/emaberto/ article/viewFile/3431/2062>.Acesso em: 15 mai. 2015.

GROSFOGUEL, Ramón. Para descolonizar os estudos de economia política e os estudos pós-coloniais: transmodernidade, pensamento de fronteira e colonialidade global. 2008. Revista Crítica de Ciências Sociais, n. 80, p. 115-147.

MIGNOLO, Walter. A colonialidade de cabo a rabo: o hemisfério ocidental no horizonte conceitual da modernidade. In: LANDER, E. (Org.). A colonialidade do saber: eurocentrismo e ciências sociais. Perspectivas latino-americanas. Buenos Aires: Clacso, 2005.

QUIJANO, Aníbal. Colonialidade do Poder, Eurocentrismo e América Latina. In: LANDER, Eduardo (Org.). A Colonialidade do Saber: eurocentrismo e ciências sociais. Perspectivas latino-americanas. Buenos Aires: Clacso, 2005.

SANTOS, Boaventura de Sousa. A Crítica da Razão Indolente: contra o desperdício da experiência. São Paulo: Cortez, 2006.

SANTOS, Boaventura de Sousa. Do pós-moderno ao pós-colonial. E para além de um e outro. Faculdade de Economia de Coimbra, Coimbra / Portugal, Conferência de abertura do VIII Congresso de Ciências Sociais, realizado em Coimbra, de 16 a 18 de setembro de 2004. Disponível em: <http://www.ces.uc.pt/misc/Do_pos-moderno_ao_poscolonial.pdf>. Acesso em: 13 abr. 2015. 
SANTOS, Boaventura de Sousa; MENESES, M. P.

(Orgs.). Epistemologias do Sul. Coimbra: Almedina, 2009.

SILVA, Jônatas Conceição da. Vozes quilombolas. Uma poética brasileira. Salvador: EDUFBA/Ilê Aiyê, 2004.

WALSH, Catherine. Interculturalidad, plurinacionalidad y decolonialidad: las insurgencias político-epistémicas de refundar el Estado. Tabula Rasa. Bogotá - Colombia, n. 9: 131-152, juliodiciembre 2008 ISSN 1794-2489), - tradução livre de João B. A. Figueiredo, 2008.

\title{
COLONIALITY AT DECOLONIALITY: SCIENCE DIALOGUES FROM A “SOUTH EPISTEMOLOGY”- AN ANALYSIS OF COMMUNITIES QUILOMBOLAS
}

\begin{abstract}
This article deals with the theme "From coloniality to decoloniality: dialogues science from a south epistemology", and its relevance is through decolonization process of colonies have been marked by changes in global relations, being these changes related quilombola people, especially quilombo communities in the central region of Rio Grande do Sul, aiming to investigate some aspects of the work the coloniality to decoloniality: science dialogues from a "south epistemology" analyzing quilombo communities. The methodology of this article is based on a literature search, which can be understood as a systematic study developed based on published materials relevant authors to substantiate the selected theme, it is possible to report and evaluate the information obtained by previous research, highlighting concepts, procedures, results, discussions and relevant conclusions.
\end{abstract}

Keywords: Coloniality. Decoloniality. Epistemology. 